\title{
Tricuspid Valve Replacement
}

National Cancer Institute

\section{Source}

National Cancer Institute. Tricuspid Valve Replacement. NCI Thesaurus. Code C50816.

Surgery performed with the purpose of replacing a degenerated, calcified, malformed, dysfunctional, etc. tricuspid valve with bioprosthetic, homograft or autograft valve. 